\title{
A construção do docente encarnado na experiência da ação corporal: perspectivas para a preparação profissional para a educação infantil
}

\author{
Luciene Teixeira Diniz* \\ Roberto Gimenez ${ }^{* *}$
}

\begin{abstract}
Resumo
O presente estudo tem por objetivo discutir o papel atribuído ao corpo e ao movimento nos cursos de formação docente. Os estudos sobre a formação docente demonstram que os saberes profissionais são integrados e utilizados nas tarefas dos professores em função das contingências da área educacional. A partir desta premissa o sujeitodocente, na sua prática, é um sujeito com histórias, trajetórias e expectativas, sendo todos esses aspectos assimilados e incorporados nas suas estruturas corporais. Em especial, atribui-se ênfase ao período da educação infantil, uma vez que as representações que os professores têm sobre o seu corpo e seus movimentos seriam preponderantes para determinar sua prática pedagógica. Conceitos como mente incorporada e cognição em ação serão apresentados para discutir a construção do sujeito docente pela ação corporal, como condição necessária para o exercício de sua atividade profissional na educação infantil.
\end{abstract}

Palavras Chaves: Sujeito; Educação; Corpo; Educação Infantil; Preparação Profissional.

\section{The construction of teacher incorporated in body action experience: prospects for professional preparation for early childhood education}

\begin{abstract}
This study aims to discuss the role assigned to the body and movement in teacher preparation courses. Studies on teacher education show that professional knowledge are integrated and used in teachers' tasks depending on the contingencies of the educational area. From this premise the subject-teaching in their practice is a subject with stories, trajectories and expectations, all of which are assimilated aspects and incorporated in their body structures. In particular, emphasis is attributed to the period of early childhood education, as the representations that teachers have about your body and its movements would be predominant in determining their practice. Concepts such as incorporated mind and cognition in action will be presented to discuss the construction of the subject teacher by bodily action as a necessary condition for the exercise of their professional activity in early childhood education. Keywords: Subject; Education; Body; Childhood Education; Professional Preparation
\end{abstract}

\section{Introdução}

A insatisfação dos professores no contexto educacional tem sido objeto de estudo cada vez mais frequente nos últimos anos, tanto no Brasil como em outros países. O pesquisador espanhol José Manuel Esteve Zaragoza (1999), acredita que a crise da profissão docente supera os limites territoriais dos países e torna-se internacional. O referido autor utiliza a expressão "mal-estar docente", para discutir os sintomas que contribuem para que tantos docentes estejam passando pelo desencantamento com a área.

Para ele, esse "mal-estar docente" é um fenômeno de proporções cada vez mais abrangentes e diz respeito a um aspecto crucial para o exercício da profissão, o "prazer pela docência", ou seja, o envolvimento com o trabalho; a percepção de reconhecimento; a valorização da atividade docente por parte dos alunos, das instituições; a garantia de condições satisfatórias de trabalho e de salário

\footnotetext{
*Endereço eletrônico: luciene.diniz@unicid.edu.br

***Endereço eletrônico: roberto.gimenez@unicid.edu.br
}

condizente com o esforço; enfim, tudo o que se refere ao bem-estar do professor. (BONDÍA, 2002).

Lapo e Bueno (2002) discutiram a multiplicidade de fatores que podem contribuir para o que hoje podemos chamar de uma evasão docente. Seu trabalho foi baseado nas histórias de vida profissional de ex-professores. Este trabalho indica que, desde a mudança no milênio, houve aumento de $300 \%$ nos pedidos de exoneração do cargo de professor no território nacional. Para as autoras, esse fenômeno seria desencadeado por uma multiplicidade de fatores, dentre os quais é possível destacar os baixos salários, as instalações físicas precárias, o desprestígio profissional, o enfraquecimento ou relaxamento dos vínculos com a escola e a insatisfação nas relações com os alunos. Uma das constatações deste estudo é o de que embora os fatores de ordem externa fossem determinantes para o abandono, tais como o salário e as condições de trabalho, sobretudo para aqueles profissionais que 
apresentavam vários anos de experiência no magistério, esse abandono, em grande parte dos casos, foi motivado por disposições internas dos professores, como a incapacidade para lidar com fatos e acontecimentos vivenciados cotidianamente. Esta premissa é reforçada pela constatação de que o abandono não acontece repentinamente, mas em várias etapas, em geral muito difíceis e conflituosas, que são vividas pelo docente até que ele tome a decisão de deixar definitivamente a profissão.

Em parte essa discussão, merece uma atenção especial na Educação Infantil, contexto que tem sido alvo de debate, sobretudo no que diz respeito aos impactos das mudanças sociais nas configurações das escolas, na relação entre os pais e as crianças e no relacionamento que se estabelece entre pais e professores (p.e. BASTOS, 1999; GIMENEZ; SILVA, 2014).

Em alguns casos, o abandono profissional seria determinado pelo excessivo número de alunos por turma, resultando num consequente desgaste físico. Cumpre ressaltar ainda as dificuldades para identificar mudanças consideráveis no processo de aprendizagem das crianças. Ou seja, a frustração associada aos efetivos impactos de sua atividade profissional também contribuiria para um descontentamento com a profissão.

Não é recente a defesa que os espaços onde ocorrem as práticas pedagógicas para a educação infantil devam ser revisitados levando-se em consideração o papel das experiências motoras para a construção do conhecimento da criança (MUSEN; CONGER; KAGAN; HUSTON, 1995; VALSINER, 1997). De modo geral, defende-se que uma reorientação das práticas pedagógicas contribuiria para as possibilidades de aprendizagem das crianças, criando condições para práticas pedagógicas baseadas na interdisciplinaridade.

Vale ressaltar que o papel das experiências motoras é validado por instrumentos oficiais como os próprios Referenciais Curriculares Nacionais para a Educação Infantil (1998). De acordo com o referido documento orientador, podem ser destacados dois grandes objetivos para este ciclo da vida escolar, quais sejam: (a) o ganho de autonomia; (b) o conhecimento do mundo. O primeiro objetivo estaria associado fundamentalmente ao almejado ganho de independência associado ao ingresso na escola e a uma preparação para o ingresso no Ensino Fundamental. Por outro lado, o segundo estaria associado à missão que a Escola apresenta de promover a apropriação do mundo por meio do desenvolvimento de diferentes competências, como aquelas associadas à matemática, à linguagem, à arte, à compreensão da natureza, da vida em sociedade e ao "movimento humano".

Um fator que chama a atenção refere-se ao fato de que, mesmo diante de uma série de dificuldades que contribuem para o abandono da profissão e das inúmeras possibilidades oriundas das atividades motoras desenvolvidas junto às crianças, em geral, os profissionais que desenvolvem projetos junto à Educação Infantil pouco propõe atividades motoras para estas crianças.

Gimenez (no prelo) desenvolveu o estudo junto a 102 pedagogos com menos de dois anos de experiência na Educação Infantil e estudantes de pedagogia do último semestre com a intenção de investigar as representações sociais de corpo e movimento por parte de profissionais da Educação Infantil. A partir deste trabalho, constatou-se a seguinte percepção acerca do componente curricular Educação Física e das atividades motoras:

- $37 \%$ dos professores/estudantes de pedagogia não propunham práticas corporais em suas aulas;

- $42 \%$ dos professores/estudantes de pedagogia não se consideravam capacitados para ministrar essas práticas;

$-54 \%$ dos professores/estudantes de pedagogia consideravam esse conhecimento como dispensável ou menos importante;

- $65 \%$ dos professores/estudantes de pedagogia julgavam que esse tipo de conhecimento deveria ser substituído por outro mais relacionado às efetivas demandas da Educação Básica.

$\mathrm{O}$ autor atribuiu esses resultados a uma série de fatores, quais sejam:

(1) Muitas professoras da Educação Infantil apresentaram experiências negativas associadas a movimento e corpo em sua trajetória de vida. Existem muitos relatos de professoras argumentando que eram as últimas a serem escolhidas no time, que não gostavam de correr em torno da quadra. Este fator também estaria associado a uma baixa percepção de competência motora por parte destes profissionais.

(2) Há uma representação social de Educação Física associada ao gesto tecnicamente perfeito e cujo desempenho motor é hegemônico sobre outros níveis e tipos de aprendizagem. Em especial, trata-se de uma herança militar da área da educação física e cujas metodologias de ensino, em muitas ocasiões foram excludentes. Esta representação social, ainda hoje, é reforçada por diferentes profissionais. 
(3) Hipervalorização social do corpo e baixa autoestima em relação ao corpo. Em face da "corpolatria" - valorização midiática do corpo típica de uma sociedade de consumo -, identificase a existência de uma grande pressão nos mais diferentes contextos em torno da apresentação física das pessoas. Prevalece uma grande valorização social das figuras longilíneas e dos indivíduos esbeltos. Considerando que a figura do professor está em constante evidência pela sua atividade profissional, é possível que muitas professoras/estudantes evitassem a proposição destas atividades para não evidenciar algumas de suas dificuldades motoras ou particularidades físicas.

Ao se levar em consideração os impactos da história de vida do professor na orientação de sua prática pedagógica, cumpre ressaltar o papel das mediações pelos cursos de graduação neste processo de formação. Tardif (2002), por exemplo, instiga uma reflexão acerca da realidade da escola. Pare ele, os próprios dilemas estariam na "fragilidade da profissão docente". Estamos tratando de um sistema educacional ultrapassado e de uma formação de professores que não acompanha as novas e complexas exigências sociais, pedagógicas e culturais, advindas da globalização e da velocidade da informação. $O$ presente artigo parte do pressuposto que isto também aconteceria em razão das próprias experiências prévias de alguns pedagogos com as práticas corporais. Contudo, a compreensão dessa possível influência na formação, merece ser discutida a partir do conceito de formação do sujeito docente.

\section{Formação do sujeito docente}

Até chegar aos seus dilemas típicos dos contextos profissionais, a construção docente passa por processos, que estão exatamente na nossa formação. Manoel (2011) provoca uma discussão sobre esta questão ao propor distinção em relação ao que considera "preparação" e "formação" profissional. Para Manoel (2011) as duas incidem uma sobre a outra, mas acontecem em tempos diferentes. Para o pesquisador a preparação profissional compreende um período finito, onde o começo, meio e fim, são bem definidos. Por meio dela, ocorreria a obtenção dos conhecimentos, meios, técnicas e habilidades da profissão escolhida. Já a formação não tem começo, meio e fim definidos, ela se inicia nos primórdios da historia de cada individuo, passa pela sua infância, juventude e fase adulta. Os dilemas docentes não dizem respeito somente à preparação profissional, mas também a formação. A formação abarca assim situações e vivências que incidem sobre a preparação profissional.

Tardif (2002) propõe uma série de saberes inerentes aos docentes. Em especial dois deles podem contribuir ao escopo desta discussão: (1) os saberes da formação profissional, que são aqueles relacionados aos conjuntos teórico-conceituais das ciências da educação, as ideologias pedagógicas dominantes, presentes nas instituições de formação. Esses saberes estão presentes em concepções acerca da função social do ensino e das escolas de educação básica e permeiam o discurso dos professores formadores; (2) os saberes experienciais, questão relacionados à prática cotidiana do professor, feita por meio de sua experiência individual de atuação, quando entra numa sala de aula e encontra universos não prescritos, mas sim percebidos pela sua visão singular e formados por um serie de aspectos, como a sua formação, a cultura local, por suas deliberações e motivações. Para este autor, os saberes profissionais relacionam-se direta e necessariamente com a construção de saberes experienciais. Essa noção, por sua vez, problematiza a prática docente e supera a dissociabilidade de teoria e prática, principalmente pelo fato de articular a origem dos diferentes tipos de saberes e colocá-los num mesmo plano de análise.

Neste sentido, os dilemas dos docentes aparecem na construção da sua subjetividade, são formados pelos aspectos da sua preparação profissional e da sua formação. Como afirma Manoel (2011), a formação e a preparação profissional se confundem com a própria historia de vida do individuo. Para o pesquisador a formação e a preparação profissional podem ser reunidas em uma única palavra: experiência.

Ao perceber essa realidade, e ao se estabelecer como sujeito na sua experiência, o docente pode ser ativo na construção da sua história e passa a estar "presente" na sua formação. O estar presente refere-se a estar consciente da sua experiência. Estar na sua experiência é estar presente no seu processo de formação, que deve ser compreendido como um ciclo que não começa com o ingresso de cada professor na escola e termina no final de sua trajetória profissional, mas sim desde seu nascimento e passa por toda a sua vida. Assim, a subjetividade se traduz quando cada pessoa vai assumindo o papel de sujeito de sua própria história e como ela se articula com a história coletiva e 
global. A utilização dessa compreensão de sua subjetividade faz com que o sujeito dentro da área educacional se construa como sujeito-docente.

Inexoravelmente, a prática docente é compreendida não somente como um espaço de aplicação de saberes provenientes da teoria, mas como um espaço no qual o docente se depara com situações singulares, imprevisíveis e complexas, nas quais é preciso lançar mão de saberes específicos oriundos de suas próprias vivências.

No bojo desta argumentação entende-se que as experiências motoras seriam cruciais na consolidação do conhecimento do professor e, consequentemente, na formação docente para atuação na educação básica, tema discutido na própria seção.

\section{Algumas considerações sobre a "cognição encarnada" na formação do sujeito-docente}

Descartes (1992) foi quem reforçou mais a distinção entre mente e corpo influenciando, consideravelmente, as abordagens científicas sobre $o$ corpo ao limitar apenas dois os modos de existência: como coisa, ou objeto, e como consciência. Vários conceitos, advindos das análises clássicas sobre o corpo e influenciadas pelo cartesianismo, especialmente na Fisiologia e na Psicologia, reduziram a dimensão do universo corporal ao conhecimento de suas partes ou ao direcionamento psíquico. Além disso, herdamos na nossa formação essa fragmentação que interfere na forma de nos observamos na nossa integridade.

A compreensão deste corpo no contexto histórico pressupõe considerar que a subjetividade docente envolve processos mentais compostos de estruturas que foram incorporadas no corpo, e essas estruturas dão base para a ação da prática profissional (DAMÁSIO, 1995). Diante desta perspectiva a noção de sujeito nos remete a uma nova concepção de corpo.

Merleau-Ponty (1992) também aponta uma critica ao modelo do corpo objeto, defendido pela visão cartesiana. Para ele, a cognição depende da experiência que acontece na ação corporal. Essas ações corporais estariam vinculadas às capacidades de movimento, da motricidade, opondo-se à compreensão de cognição só como processamento de informações. Em suas obras (MERLEAU-PONTY, 1994; 1997), este filósofo apresenta diferentes perspectivas para a compreensão humana, como a do corpo sujeito, com uma critica ao modelo do corpo objeto, defendido pela visão cartesiana e a perspectiva da corporeidade, fundada no corpo em movimento e toda complexidade dos processos corporais do ser humano em movimento; e o arranjo de todos esses aspectos para refletir o conhecimento do ser e a experiência humana. Merleau-Ponty relaciona o corpo à perspectiva da consciência. Para ele, a consciência é compreendida, não à maneira dualista, mas dimensionada pelo corpo, via universo da percepção, compreendida como movimento. Assim a "consciência do corpo" seria compreendida como conhecimento do corpo. Esse conhecimento não é intelectual, uma imagem idealizada, mas um conhecimento perceptivo possibilitado pelo movimento. Segundo este mesmo autor, não existe possibilidade de se compreender o corpo sem sua motricidade, sem sua capacidade de movimentar-se.

Para reforçarem o papel desta singular interação entre corpo e mente, Varela e Maturana (1995) defendem o conceito de "mente incorporada", afirmando que mente e corpo caminham integrados um ao outro, no que se refere a cognição. De acordo com a concepção desses autores, o sujeito vive em uma atuação-incorporada, o que descarta a existência de um mapa interior para a ação. Ocorreriam reestruturações sistemáticas dos estímulos segundo os esquemas formados no corpo e pelo corpo. Sendo assim, a mente refaz o mundo segundo o corpo.

Por meio de seu corpo, o sujeito vai assimilando e se apropriando dos valores, normas e costumes sociais, caracterizando um processo contínuo de incorporação. Mais do que aprendizado intelectual o sujeito quando vive as suas experiências adquire um conteúdo cultural, que se instala no seu corpo, nas suas expressões, no seu gesto, no seu comportamento.

Esta visão rompe com o que Morin (2007) aponta como concepção histórica que gerou um dos problemas do sujeito hoje, a incapacidade de reconhecer e de aprender a complexidade do real. Isto teria ocorrido pela dificuldade que o ser humano de organizar seu conhecimento. Segundo o autor, isto caracteriza o princípio da disjunção. Para ele, uma das disjunções que mais afetam o processo educacional corresponde à dicotomia "CorpoMente". Esta concepção afetaria a visão de corpo, muito vezes, ainda excluido do processo de organização do conhecimento, do contexto educacional e da construção como sujeito-docente. Em síntese, seria possivel considerar que estamos hoje desencarnados do nosso desejo docente, vivemos uma educação desencarnada.

A experiência do corpo em movimento ajuda-nos a compreender os sentidos, os conceitos, 
os costumes, a cultura de um modo geral. Por meio das diferentes possibilidades de expressões corporais podemos compreender a indeterminação da existência, a qual tem vários sentidos, elaborados na relação consigo mesmo, com o outro, com o próprio mundo. O corpo encontra-se recortado pela sua história.

A motricidade aqui não é uma serva da consciência, que transporta o corpo ao ponto do espaço que nós previamente representamos. A motricidade é sim o aspecto primário em que se organiza o sentido de todas as significações no domínio do espaço representado em um contexto histórico.

Diante dessas argumentações seria possível pressupor que a construção do sujeito docente presente na sua experiência pode ser concebida pela via corporal. É importante entendermos que a construção da subjetividade docente envolve processos mentais compostos de estruturas que foram incorporadas no corpo e essas estruturas dão base para a ação da prática profissional.

Vale ressaltar que a dicotomia corpo e mente presente na concepção atual de educação também é acompanhada por outras dicotomias. A relação do sujeito com a sua experiência recebe influências como as que historicamente são identificadas na Filosofia e na ciência. Os campos de conhecimento foram influenciados pela distinção entre sujeito, o que conhece, e o objeto o que é o conhecido. Assim, ao se distinguir do objeto o sujeito se despe da sua experiência (MANOEL, 2011). Um dos pressupostos é o de que essa dificuldade do homem estar presente na sua experiência também seria resultado do conhecimento científico, que durante muito tempo dissipou a aparente complexidade dos fenômenos a fim de revelar a ordem simples a que eles obedecem (MORIN, 2007).

Varela, Thompson e Rosch (2003) acreditam que hoje a questão mente e corpo criou a experiência de estarmos habituados a dissociar o nosso corpo da nossa mente, e podemos não ter consciência de onde estamos e daquilo que o nosso corpo ou a nossa mente estão a fazer. É o nosso hábito de desatenção da nossa experiência, de quem somos, das nossas respostas, de estar consciente da nossa integração. Para esses autores (2003) é possível desenvolver hábitos em que o corpo e a mente se encontrem perfeitamente coordenados, contudo, para que isso aconteça o sujeito deve estar presente na sua experiência.

A construção de um sujeito-docente é assim apresentada pela integração entre mente e corpo, na qual a cognição acontece na experiência vivida pela ação corporal, e não existe separação entre a cascata de eventos do organismo, o corpo e o ambiente. Nesta mesma linha a abordagem de Johnson e Rohrer (2006), conhecida como "realismo incorporado" ou "realismo encarnado" ("embodiedrealism"), propõe em contraste com as teorias representacionistas, que defendem que o conhecimento está na mente como um espelhamento e rejeita a noção segundo a qual mente e corpo sejam duas unidades ontologicamente distintas. O realismo encarnado recusa o ponto de vista em que cognição e linguagem se baseiam em representações simbólicas na mente e espelha os objetos do mundo físico exterior.

Segundo a noção de mente incorporada e realismo encarnado, cognição é ação. Para essas linhas não existem fenômenos cognitivos que sejam desprendidos do corpo, como atos mentais simplesmente situados na mente do sujeito, ou pelo simples mecanismo de estimulo e resposta.

A hipótese é que as representações mentais da atividade cognitiva estão arraigadas no corpo, mediante esquemas incorporados adquiridos pela ação do corpo no mundo físico, material e concreto. Estes esquemas são ativados no córtex sensóriomotor e são responsáveis por moldar a cognição, mesmo quando ela aparenta ser puramente abstrata ao olhar do observador, ou um simples mecanismo de estímulo-resposta.

Assim, o sujeito vive em uma atuaçãoincorporação ou um "realismo incorporado". Não existe a elaboração de um mapa interior para a ação. O que ocorre é uma reestruturação do estímulo segundo os esquemas formados no corpo e pelo corpo, sendo assim, a mente refaz o mundo segundo o corpo.

A cognição emerge de processos incorporados de um organismo em constante adaptação, por meio de seus esquemas incorporados, para dar conta das mudanças ambientais. A mente nunca está separada do corpo, mas é sempre uma cadeia de atividades incorporadas imersas num fluxo de interações organismo-meio, que constituem a experiência. Existe uma congruência entre corpo, ambiente e sistema nervoso e essas nunca serão as mesmas, uma vez que estamos em constante mudança. As experiências desta congruência corpo, ambiente e sistema nervoso geram esquemas que o corpo podem utilizar para suas ações.

É diante desta perspectiva é que se defende que esta dimensão deva ser levada em consideração nos cursos de formação docente para a educação infantil. Sobretudo, ao se levar em consideração que, 
em muitos desses cursos, a dimensão motora é frequentemente ignorada.

\section{Formação do sujeito-docente: considerações para cursos de formação profissional}

O sujeito-docente encarnado na sua experiência não pode ser mais compreendido como um mero transmissor de conhecimentos, que exerce sua prática pedagógica de modo repetitivo, que traduz conhecimentos específicos e fragmentados, a partir do discurso científico das ciências da educação. Todavia é possível concebê-lo como produtor de saberes, dado que os saberes são provenientes da sua experiência.

Um caminho possível para pensarmos a construção do sujeito-docente encarnado na sua experiência seria uma mudança de perspectiva nos cursos de formação de professores. Manoel (2011), por exemplo, defende um caminho que não o das dicotomias. Ele argumenta que os cursos de formação giram em torno de dicotomias como teoria e prática, ciência e intervenção, conhecimento básico e conhecimento aplicado, e cita até o que observa como uma dicotomia não reconhecida, que se estabelece entre professor e aluno. Corroborando a perspectiva de Manoel, Gimenez (2011) destaca a necessidade de que os cursos de formação docente busquem instigar os estudantes à solução de problemas por meio do estímulo ao estudo a partir de situações desafiadoras e uma das dimensões consideradas deva ser, de fato, a procedimental.

Estas constatações apresentadas nos fazem pensar que o modelo de formação profissional frequentemente utilizado nos cursos de preparação profissional não atenda às demandas da mudança, as quais pressupõem considerar as interdependências, as interações e integrações do sujeito.

Gimenez e Silva (2014) acreditam que o modelo de formação profissional para a atuação na Educação Básica é linear e reflete uma concepção fragmentada de conhecimento que não valoriza o processo contínuo de aprendizagem. Nesta mesma direção cabe recordar que o sujeito-docente encarnado na sua experiência está em um processo constate de formação, estamos falando de um sujeito ativo.

O debate contemporâneo acerca da formação docente indica caminhos para uma reformulação de teorias e para a construção deste novo paradigma. Os principais temas abordados giram em torno do reconhecimento dos saberes docentes, do desenvolvimento de uma prática reflexiva, da promoção, da autonomia intelectual, da formação contínua centrada no exercício profissional, da construção de uma nova identidade docente, em direção à profissionalização, refletem sobre a necessidade de um sujeito encarnado na sua experiência. É preciso dar chance à experiência para que o sujeito possa experimentar (MANOEL, 2011).

De modo geral, percebe-se que na preparação profissional do professor são seguidos roteiros prontos, o que não permite que o aluno passe pela experiência de construir seu processo e conhecimento. Assim os cursos de formação devem confrontar a cada momento a experiência de formação da subjetividade: é a formação realizada, o que cada sujeito vive e experimenta, isto é, a subjetividade plenamente constituída na experiência.

Esta problemática também passa pela negação do corpo na educação. O curso de Educação Física não deve ser o único a pensar no corpo, todos os cursos de formação de professores na educação, precisam olhar o corpo no processo de formação.

Os contextos educacionais assim como a vida exigem um sujeito flexível, com grande capacidade de adaptação, que seja capaz de solucionar problemas, isso só é possível se pensarmos em uma formação e preparação profissional que considera a não linearidade, as incertezas, as mudanças e a adaptação. Segundo Gimenez e Silva (2014), isto não implica em descartar a organização salutar ao andamento do projeto pedagógico, mas sugere a necessidade de repensar a matriz de formação e as metodologias utilizadas em sala de aula.

Diante das demandas atuais da Educação Básica, o pressuposto é o de que se essas considerações não fizerem parte da agenda de discussão para a formação docente, poder-se-ia comprometer o processo de formação por meio de uma graduação esvaziada (SILVA, 2001).

\section{Considerações Finais}

É preciso considerar que a subjetividade docente é construída por uma serie de rupturas e os novos começos fazem parte de um processo de formação do sujeito. Esse trabalho considerou que o processo de formação de sujeitos-docentes deve ser compreendido como um ciclo que começa no nascimento do sujeito até o final da sua vida. Em meio a este processo é possível destacar o curso de preparação profissional, as práticas cotidianas na escola e também toda a história do docente. Esse ciclo de experiências e vivências é incorporado no 
corpo de cada sujeito e também é pela ação corporal que o docente constrói a sua trajetória.

Diante destas constatações, abordou-se a importância de mudanças de perspectivas nos cursos de Formação de Professores, que ainda estão vinculados a antigos paradigmas que ainda pensam e acentuam divisões, diferenças e disjunções. Esta mudança paradigmática pode colaborar para a eliminação da famigerada e histórica separação entre a teoria e a prática docente, ou, em outras palavras, entre aquele que conhece e o conhecimento.

O entendimento desta obra é o de que o sujeito encarnado na sua experiência é o sujeito que vive em um corpo, pelo movimento, e nesta ação incorporada ele constrói seus saberes como docente, como um sujeito ativo e presente no seu tempo.

Assim, é possível considerar que atualmente, a experiência pedagógica cursos de formação docente aconteça em modelos padronizados, vivenciadas por sujeitos desencarnados da sua experiência. A subjetividade docente deve ser construída por um sujeito encarnado, marcado por incongruências, incertezas e descontinuidades, que o leva a inventar (ou reinventar) a educação a todo instante.

\section{Referências}

BASTOS, M. A criança no terceiro milênio. In: Krebs, R.J.; COPETTI, F; BELTRAME, T.S. \& ULSTRA, M. (Eds). Perspectivas para o desenvolvimento infantil. Santa Maria: Edições SIAC, 1999. p. 183-194.

BONDÍA, J.L. Notas sobre a experiência e o saber da experiência. Rev. Bras. Educ. n.19, p.20-8, 2002. Disponível em: <http://www.anped.org.br/rbe/rbedigital/RBDE19/R BDE19_04_JORGE_LARROSA_BONDIA.pdf >. A cesso em: 01/05/2015

DAMÁSIO, A. O erro de Descartes. São Paulo: Companhia das Letras, 1995.

DESCARTES, R.. Meditações sobre a Filosofia Primeira - Meditações Metafísicas. São Paulo: Almedina, 1992.

GIMENEZ, R. Século XIX: conquistas e desafios na formação de professores de educação física: In: GIMENEZ, R.; SOUZA, M. T. (Org.). Ensaios sobre contextos da formação profissional em Educação Física. Várzea Paulista, SP: Fontoura, 2011. p.73-82.

GIMENEZ, R. e SILVA, M.H.A. Formação de professores para a educação básica: revisitando concepções e práticas pedagógicas por meio do prisma de teorias da complexidade. Revista Ambiente@Educação,v.7,n.2, p.268-76, 2014.

JOHNSON, M; ROHRER, T. We are live creatures: Embodiment, American Pragmatism, and the Cognitive Organism. In: Zlatev, Jordan et al. (Eds.). Body, language and mind. (pp.97-132). Berlim: Mouton de Gruyter, 2006.

LAPO, F.R; BUENO, B.O. O abandono do magistério: vínculos e rupturas com o trabalho docente. Psicologia USP, 2002, v. 13, n.2, p. 243276.

MANOEL, E.J. Formação de professores: A necessidade da experiência, a experiência da complementaridade. In: GIMENEZ, R.; SOUZA, M.T.(Org.). Ensaios sobre contextos da formação profissional em Educação Física. Várzea Paulista, SP: Fontoura, 2011. p.99-126.

MATURANA, H. e VARELA, F. A árvore do conhecimento: as bases biológicas do entendimento humano. Campinas: Editorial Psy II, 1995.

MERLEAU-PONTY, M. O Visível e o Invisível. 3a ed. São Paulo: Editora Perspectiva, 1992.

. Fenomenologia da Percepção. São Paulo: Martins Fontes, 1994.

1997.

O Olho e o Espírito. $2^{\mathrm{a}}$ ed. Lisboa: Vega,

MORIN, E. Introdução ao pensamento complexo. Tradução de Eliane Lisboa.Porto Alegre:Sulina, 2007.

MUSSEN, P.H.; CONGER, J.J.; KAGAN, J. \& HUSTON, A.C. Desenvolvimento e personalidade da criança. São Paulo, Harbra, 1995.

ROHRER, T. Image Schemata in the Brain. In: Beate, H. e Grady, J. (Eds). FromPerception to Meaning: Image Schemas in Cognitive Linguistics. (pp. 165-196). Berlim: Mouton de Gruyter, 2005. 
SILVA, F. L. e. A perda da experiência da formação na universidade contemporânea. Tempo Social: Revista de Sociologia da Universidade de São Paulo. S. Paulo, v.13, n.1, p. 27-37, 2001.

TARDIF, M. Saberes Docentes: Formação Profissional. Petrópolis: Vozes, 2002.

Os professores enquanto sujeitos do conhecimento: subjetividade, prática, e saberes no magistério. In: CANDAU, V. M.(Ed). Didática, currículos e saberes escolares. 2. ed. Rio de Janeiro: D P\& A, 2000.

VALSINER, J. Culture and devolopment of children's action. New York: John Wiley \& Sons, 1997.

VARELA, F. Ethical Know-how: Action, Wisdom and cognition. Stanford: Stanford University Press, 1999.

VARELA, J.F.; THOMPSON, E.; ROSCH, E.. Amente corpórea: Ciência Cognitiva e experiência humana. Lisboa: Instituto Piaget, 2001.

ZARAGOZA, J.M.E. O mal-estar docente: a salade-aula e a saúde dos professores. São Paulo: EDUSC, 1999.

\section{Sobre os autores}

Luciene Teixeira Diniz: Mestre em Educação: Formação de sujeito pela Universidade Cidade de São Paulo. Docente dos cursos de Pedagogia e Educação Física da Universidade Cidade de São Paulo.

Roberto Gimenez: Doutor em Educação. Docente e Pesquisador do Programa do Mestrado em Educação da Universidade Cidade de São Paulo/Coordenador do Curso de Educação Física da Universidade Cidade de São Paulo.

Recebido em julho de 2015.

Aprovado em fevereiro de 2016. 